\title{
Foreword
}
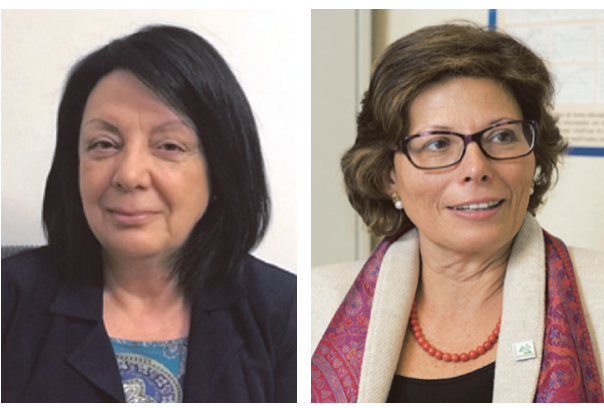

\section{The Trend of View of IRPA Professionals on Implications of Implementation of Dose Limits to the Eye Lens}

\author{
Marie Claire CANTONE *1 and Merce GINJAUME*2
}

Since the publication in 2011 of the ICRP recommendations ${ }^{1)}$ for a reduction of the equivalent dose limit for the lens of the eyes for workers, IRPA has organised three surveys addressed to the IRPA Associations (AS) to collate the practitioners' experiences and concerns in the implementation of the ICRP recommendations. The surveys were launched in 2012, 2015 and 2018. ${ }^{2-6}$

The documents reporting the results of the surveys and the IRPA guidance on implementation of eye dose monitoring and eye protection of workers, are all available in the IRPA web site (https://irpa.net) at the page dedicated to the topic lens of the eye. The evolution of the answers illustrates the progress in the implementation of the new limit.

Answers for the first survey were received from 12 AS, covering 16 countries; the second and the third survey received answers respectively from: 22 AS covering 40 countries; 26 AS and 10 organizations/institutions, covering a total of 44 countries from Africa, North and South America, Asia/Australia, and Europe.

The questionnaires were based on a number of questions concerning the different areas of practice, over principal topics, as: -implications for monitoring and assessing lens dose; -implications for methods of protection; -wider implications of implementing the revised limits. Moreover, in the second and third survey an additional topic was included regarding legislative processes activated or considered to be, in relation to the new limit, and the attention is addressed also to the wider issue of tissue reactions with attention to circulatory diseases, because of the higher incidence of injuries occurring at lower doses than reported previously.

The responses received in the first survey expressed considerations on different aspects for potential cost implications, as: -additional dosimetry, shielding and training; -possible need for extra staff if current specialists staff reach the dose limit; and -enhanced medical examinations for workers. A number of recommendations emerged from the fist survey, including: -the request for more understanding about the relationship between exposure of the lens of the eye and cataract formation, and further guidance to assist implementation; -the need to propose or define procedures related to the employment of people with existing or precataract conditions; and -the practical aspects related to dosimetry and protective equipment.

From the second survey, it emerged that the AS were no longer focused on the motivations of the significant reduction of the dose limit, as they were in the first survey, but more focused on the implication in dosimetry: from additional dosimeters to monitor the eye dose to dose recording for itinerant workers; from possible differences in provision of dosimeters, and to the responsibility for collation of doses.

It emerged that the drastic reduction in the dose limit needs due time to be implemented and applied, since it will deeply change some previously consolidated operating procedures, but nevertheless the community is gradually progressing along the path towards the implementation. Moreover, the application of the new limit will generate additional costs, and it is recognised that the size of the increase and the types of cost are uncertain.

\footnotetext{
*1 University of Milan, Milan, Italy.

*2 Institut de Tecniques Energetiques, Universitat Politecnica de Catalunya, Barcelona, Spain.
} 
The third survey shows that the introduction of the annual dose limit of $20 \mathrm{mSv}$ for the eye is well underway in most countries, although not all countries intend to adopt this limit in the near future.

Compared to previous surveys, there has been a continuous and significant activity in view of an implementation. It is well recognised in this survey the need for well-defined, and comprehensive procedures governing all aspects of protection and how training and education are essential for an appropriate use of protections and for raising awareness. Moreover, as already evident with the second survey, it is clear that data and information about risk have to be given to patients in case of procedures with potentially high dose to the eyes.

A series of specific recommendations emerged from the responses received from IRPA AS, in particular referring to the $2^{\text {nd }}$ and $3^{\text {rd }}$ survey, ${ }^{5,6)}$ specifically with reference to the following main subjects: regulatory and scientific aspects; dose reduction, dosimetry and protection aspects; cost implications; awareness, education and training; and consideration of tissue effects other than eye lens effects.

The three surveys aimed to promote a wide exchange of experiences at an international level, on the impact of the change in dose limit for the lens of the eye and its implementation with regard to occupational exposure. To that end efforts were made to obtain as large a participation from the RP community worldwide as possible, to determine views and actions taken since the 2011 ICRP recommendation for revision of the limit.

It is certain that a number of questions remain open: the elapsed time since the start of the first IRPA survey has been insufficient to create a profoundly different picture with every aspect resolved.

\section{REFERENCES}

1) International Commission on Radiological Protection 2012 ICRP statement on tissue reactions/early and late effects of radiation in normal tissues and organs - threshold doses for tissue reactions in a radiation protection context. ICRP Publication 118, Ann. ICRP, 41 (1/2) (2012).

2) J. BRoughton, M. C. CANTONE, M. GINJAUME and B. SHAH; Report of Task Group on the implications of the implementation of the ICRP recommendations for a revised dose limit to the lens of the eye. J. Radiol. Prot., 33, 855-868 (2013).

3) J. BROUGHTON, M. C. CANTONE, M. GINJAUME, B. SHAH and R. CZAEWINSKI; Implications of the implementation of the revised dose limit to the lens of the eye: the view of IRPA professionals. Ann. ICRP, 44, 138-143 (2015).

4) J. BROUGHTON, M. C. CANTONE, M. GINJAUME, B. SHAH and R. CZAEWINSKI; Implications in dosimetry of the implementation of the revised dose limit to the lens of the eye. Radiat. Prot. Dosim., 164 (1-2), 70-74 (2015).

5) M. C. CANTOne, M. Ginjaume, S. MiljaniC, C. J MARTin, K. AKAHANE, L. MPETE, S. C. MiChELin, C. M. FLANNERY, L. T. DAUER and S. BALTER; Report of IRPA task group on the impact of the eye lens dose limits. J. Radiol. Prot., 37 (2), 527-550 (2017).

6) M. C. CANTONE, M. GINJAUME, C. J MARTIN, N. HAMADA, S. YOKOYAMA, J.-M. BORDY, L. DAUER, A. DURÀN, C. JEFFRIES, W. HARRIS, O. KASHIRINA, A. O. KOTENG, S. MICHELIN and W. SUDCHAI; Report of IRPA task group on issues and actions taken in response to the change in eye lens dose limit. J. Radiol. Prot., 40, 1508-1533 (2020). 